\title{
Mixed Methods Insights into E-Learning as Transformative Covid-19 Response in The Behaviorist Education of Oman
}

\author{
Ghania Al Kharusi \\ University of Bristol: the UK
}

\begin{abstract}
The Covid-19 pandemic has created unique problems for education as teaching and learning have had to move online. This disruptive event has had different outcomes in different educational systems. Those based on behaviourist approaches, as is the case for Gulf countries (Reimers \& Schleicher, 2020) have been hit hardest. No education system was fully prepared. There is no pandemic e-readiness model for education. By understanding students' experiences, this study helps to redress the wrongs of Covid-19 and to create a legacy by developing a model. It will contribute to preparing for a smooth transition to online learning in subsequent disasters.

I examine an example of a teacher-centred education system, the female undergraduate students in the Engineering Faculty at Sultan Qaboos University, Sultanate of Oman. This study is ground-breaking in using a mixed methods approach rather than simply quantitative research or qualitative research to analyse an education system's response to pandemic. Quantitative data give precise insights while results of qualitative research validate and corroborate the quantitative data.This paper identifies first order barriers such as the availability and accessibility of materials and devices, internet connectivity and tutors' training and secondorder barriers such as content and pedagogical strategies. It recommends key improvements to e-learning which would be crucial to a future pandemic plan. It shows the power of e-learning as a pandemic response to promote transformative learning during an emergency and possibly after it, helping change teacher-centred educational culture and turn passive students into active citizens.
\end{abstract}

Key words: e-learning, e-readiness, first-order barriers, second-order barriers, transformative learning online 


\section{Introduction}

The COVID-19 pandemic has forced the closure of schools and universities in many countries. Moving to online learning has created new problems for education. The outcomes of this sudden transition have varied among countries. It has generally gone well in cultures whose educational systems are based on a constructivist approach and which already have wellplanned integration of technology as part of learning (Reimers \& Schleicher, 2020). However, this shift has been relatively ineffective in cultures whose educational systems are based on behaviourist approaches and teacher-centred modes of education. This is the case for Gulf countries including the Sultanate of Oman (ibid). Thus, Oman is a good test-case for developing a pandemic e-readiness model effective for countries in the Middle East and beyond where behaviourist approaches are common. Pandemics and other sudden events and their consequences exacerbate inequality - we might think of the Covid-19 vaccine situation - so it is thus all the more important to find ways for areas already impacted disproportionately to respond successfully in their educational systems.

This study is innovative in both its content and the application of its method to that content. There is no pandemic e-readiness model. This study provides key elements for developing an emergency model by understanding students' experiences during the Covid-19 pandemic. The interpretation of their experiences will contribute to preparing for a smooth transition to online learning for subsequent disasters. It could provide guidelines for instructional design leading to a paradigm shift (Smith, 2012). This study is innovative. I have not seen any mixed-method research on educational responses to sudden events or on adopting e-learning in teacher-centred educational systems. (Research I have found is either quantitative or qualitative).

This paper uses the female undergraduate students in the Engineering Faculty at Sultan Qaboos University, Sultanate of Oman, as a case study. It describes the experience of learning during the pandemic and the readiness of Oman's educational system for such an emergency. It has valuable implications. It shows the potential of e-learning as a pandemic response to promote transformative learning both during an emergency and after it, helping turn teachercentred educational culture into education which more deeply engages students and their processes of thinking independently. 


\section{Methods}

\subsection{The Mixed Method}

This paper evaluates a behaviourist education system's pandemic readiness using a mixed method. In the mixed method, equal emphasis should be given to both quantitative and qualitative approaches, yet greater weight can be given to one approach (Terrell, 2012). For this study, the researcher emphasizes the quantitative approach for practical and contextual reasons. Qualitative methods validate and corroborate quantitative data. The entire mixedmethods

$$
\text { process }
$$

is

shown

below:

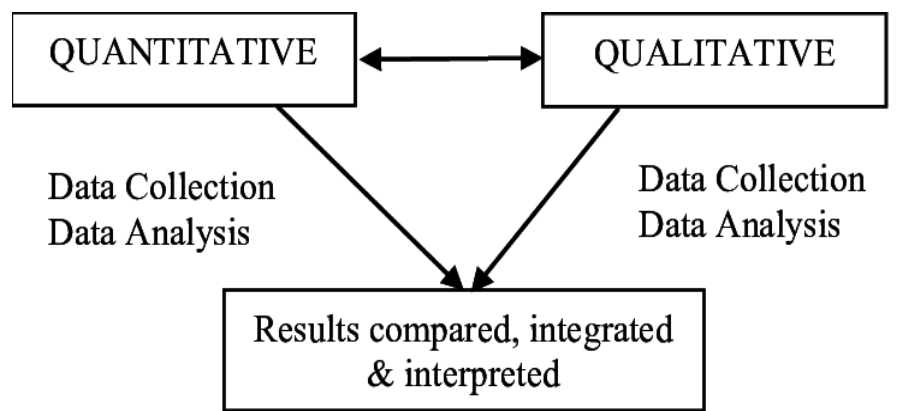

Figure: adopted from (Creswell, 2014)

Following a triangulation concurrent design, the researcher conducted five semi-structured interviews and two open-ended questions in the online survey for the qualitative strand concurrently with the quantitative strand. The aim was to enrich and explain further the statistical findings (Subedi 2016; Creswell 2009; Creswell and Stick 2006). The questions were derived from the objectives of the general aim of this study and so organized around three experiences: experience in e-learning prior to COVID-19, experience in e-learning during COVID-19, and outcomes or attitudes gained by participants from this experience. Before the interviews were conducted, experts judged the interview questions, resulting in the researcher reformulating the questions to avoid leading questions, removing complex terms, merging repeated questions, and reducing the number of questions (O'Leary, 2004).

\subsection{Quantitative Research}

This study used a web-based questionnaire featuring close-ended questions complemented by two open-ended questions. Questionnaires are a common method of data collection because they can be easily distributed without the researcher being present. Data analysis is also straightforward (Cohen, Manion \& Morrison, 2007).

I used a randomized probability and representative sampling (Matthews and Rose 2010; Denscombe 2010). Such an approach minimizes the likelihood of the researcher inadvertently compromising the objectivity of participant selection (Denscombe, 2010). I have also increased 
the response rate using 'snowballing', asking individual students to invite nominated peers to take the web-based questionnaire. This has resulted in a total sample of 208 out of a population consisting of 430, which is not ideal. However, this is not uncommon in such small-scale research projects due to time constraints. Yet the response rate was $51 \%$, which is reasonable (Merten, 2010). The cases represent female students from different levels at the Faculty which should add strength to the reliability of the sample (Munn \& Drever, 1990).

Readiness levels are measured using Aydın and Taşçı's model of "expected readiness" for elearning which is an assessment model designed using a simple code through which the reader can see levels of readiness. That is, items can be easily coded into 1,2,3,4,5, as in a five Linkert scale for which a mean score of 3.41 represents the expected level of readiness for the item, while other mean scores show either higher or lower levels of readiness. The 3.41 mean average was determined after identifying the critical level: 4 intervals $/ 5$ categories $=0.8$. As a result of this analysis, the levels of readiness were determined as depicted in (Figure 2) which interprets e-readiness along a spectrum ranging from not ready and needs lots of work, to not ready and needs some work, to ready but needs a few improvements, to ready and go ahead (Aydın \& Taşçı's 2005).

\subsection{Qualitative Research}

The qualitative part of this research project, in which participants were interviewed, used volunteer sampling. A student representative asked the students in the Engineering Faculty who might be willing to talk about their experience of learning during the pandemic (Johnson \& Christensen 2014; Teddlie \& Yu 2007).

A web-based questionnaire has been selected for data collection for six reasons: 1) convenience: Participants receive the survey instantaneously and can answer in the place and at the time of their choosing (Costley, Elliott \& Gibbs 2010; Denscombe 2010), 2) Efficiency: It saves time and money, 3) Security: using a database safeguards against data loss (Lefever et al. 2007), 4) Anonymity and privacy: participants are protected by the web-survey's built-in security systems (Denscombe, 2010; Lefever et al. 2007), 5) Accessibility: participants only need basic IT competency to take part (Lefever et al., 2007) 6) COVID-19 security: online data collection is the safest way for participants to take part currently.

The wording of the questionnaire is important and judging or piloting it plays a crucial role in its success (Cohen, Manion \& Morrison, 2007). This questionnaire was judged by four experts and two of them compared two versions of the questionnaire, English and Arabic. An Arabic--speaking proof-reader checked language accuracy in the last Arabic version. This pretesting led to some statements being clarified, repeated and irrelevant items in the research questions being removed, and other items being reorganized, and the translation being clarified. The survey was piloted further on a small group of respondents from SQU and the piloting survey was Cronbach alpha calculated to be 0.8 (Denscombe, 2010).

The questionnaire has been framed around three kinds of learning experience: first order experience, second order experience and perceptual experience (outcomes). It consists of 17 
statements to be evaluated on the 5-point Linkert scale (Keegan 2011; Boyer et al. 2006). The first dimension has 4 statements regarding students' prior skills in e-learning, university methodology, availability of resources and virtual communication opportunities (Haverila 2012). The second dimension asks students to evaluate their experience of e-learning during the pandemic in relation to transformative factors, a content factor with 6 statements regarding content availability, interactivity, collaborative tools, organization and feasibility, followed by an environmental factor, including internet services and family support. The last dimension is related to the outcomes learners gained during the experience process, and includes five statements regarding their performance, their perceptions of the program's usefulness, its ease of use, its enjoyability and its effectiveness (Liaw, 2004; Mezirow, 2003; Mezirow, 1997). A demographic profile that serves as a set of external variables and helps the researcher gain better insights into the learners' acceptance of, and readiness for, the online transition in terms of equality and social justice (Creemers \& Kyriakides 2006). The survey ended with two openended questions to get participants to add their opinions and suggestions for learning in emergencies.

Five interviews were conducted virtually over Zoom, the method identified as the safest way to reduce risk to both the participants and the researcher $(\mathrm{MoH} 2020)$. The interview was also audio recorded to help me as a researcher in engaging with the interviewees and to aid me later in the recall of discussion (Gibson, 2017; O' Leary, 2004). The researcher confirmed the interviewees' permission for the recording prior to the interview in the interview protocol and the interviewees voluntarily signed the interview consent form that ensured their confidentiality, their status as volunteers, their full freedom to withdraw or refuse to answer some questions and their protection from violation of privacy (BERA, 2018).

\subsection{Data Analysis}

Descriptive analysis was used to analyze survey data and describe the level of readiness by deriving a Mean score, standard deviation and frequency (Creswell, 2009). These helped indicate how ready the university system was and what needs further work. On a line graph the Mean for each dimension is presented in comparison to the expected level (3.4) as defined by Aydın and Taşçı's model of "expected readiness" for e-learning (Unal \& Soydal, 2014; Okinda, 2014). The analysis and visualization of the Mean were conducted using SPSS software.

\subsection{Thematic Analysis}

I came to the data with some preconceptions and with some 'analytical sensibility' as Braun and Clarke call it (2013). That is, I expected to find certain concepts reflected in the data. Therefore, I used deductive analysis in which I did not intend to develop my own framework, but instead the data are based on already existing knowledge of transformative learning where the researcher reads and interprets the data while keeping the theoretical lens active at the back of her mind (Damayanthi, 2019). The researcher is interested in students' explicit opinions; thus, I used a semantic approach in the analysis in which I did not intend to use their opinions in revealing their assumptions (Caulfield, 2019). 


\section{SILNAEDUCATION}

02-04 JULY, 2021

I followed Braun and Clarke's (2006) process of thematic analysis starting by reading over both the scripts of the interviews and the typed answers of the open-ended questions to familiarize myself with the information. Software was used for transcription to speed up the process and to enable easier development of the template that consists of extracts of the interview, codes, subthemes and themes (Damayanthi, 2019). I dealt with the transcription process as an interpretative act rather than a mechanical translation of spoken utterances into written form. I took initial notes, then compared them with the vivid notes I took during the interview. As thematic analysis is flexible, I did not need the same level of detail available in the oral recording. I therefore balanced verbatim accounts and selections from the original information by removing non-verbal clues and being selective in my transcription as my focus was on what was said rather than on how it was said (Poland, 2011).

For the open-ended questions, on the other hand, I transferred already written responses into a table. Then I interacted with the content by being reflective and then labelling descriptive codes which were 'data-driven' or semantic (Damayanthi 2019). I then organized them into a provisional template to ensure the inclusion of all codes with their extracts to show how they were used, as suggested by King (2004). Codes were put into sub-themes which were categorized into main themes. These themes were revisited and refined for the interpretation and reporting stages (Damayanthi, 2019). However, I did not follow these steps in a linear way, since rather 'it is actually an iterative and reflective process that develops over time and involves a constant moving back and forward between phases' (Nowell et al., 2017, p.4).

\subsection{Procedural ethics}

Obtaining ethical approval from the British Educational Research Association guided me in my consideration of ethical issues both prior to data collection and during the research process (BERA 2018; Costley, Elliott \& Gibbs, 2010).

I made sure to get Sultan Q University's ethical clearance for my research on their students. Further, I followed Crow and Wile's principle of treating participants with respect in writing and reporting as if in person by anonymizing each individual, thus referring to the interviewees as INT1, INT2, INT3, INT4, INT5, in reporting and as( P1, P2, P3, etc.,) in analyzing the openended questions of the survey (Crow \& Wiles 2008). This study fulfilled its ethical obligations. The landing page of the online survey outlined how participants have the right to privacy, and full personal liberty and self-determination. Participants were informed of crucial rights and responsibilities, including their competencies and responsibilities upon consenting to participate.

I outlined participants' anonymity, confidentiality and data protection were following the Data Protection Act (BERA, 2018; Creswell, 2014; Cohen, Manion \& Morrison, 2007). Participants were informed of their right to refuse to answer questions and to withdraw after submitting their data. This guarded against participants unintentionally or intentionally being the victims of the imbalanced power inherent in such data collection. The complaints procedure was outlined and contact information for the researcher made available. Finally, participants 
were made aware that by agreeing to proceed to the survey, they were giving their consent. The interview protocol emphasized audio recording and supplied interview volunteers with this information before the interview date (Creswell, 2014).

\section{Results and Discussion}

These results should be viewed in the context of some limitations. The accuracy of the overall findings may be questioned as I as a female researcher interpret findings gathered from female students in one faculty, producing one kind of gender bias whereas male participants might yield data with a different bias requiring different interpretations. Thus, the results are not generalizable. Rather, a larger sample is needed dawn from different demographic profiles including gender, social capital and family background. This enlarged sample would enrich the findings (Creemers \& Kyriakides, 2006).

Online learning provides an opportunity for a paradigm shift. Therefore, it is important to design the web-based learning according to principles of the constructivism paradigm (Liaw 2004). This is because it is not technology itself that produces effective change but the tutors' roles, instructional implementation and content design. In other words, pedagogical strategies play a crucial role in determining the success of transformative learning online (Smith, 2012). The quantitative research found that the SQU Engineering Faculty's educational e-readiness was only 2.6 which is below the expected level of readiness (measured as 3.4). Yet this evaluation could be naïve, as there is a clear difference between a well-planned online learning experience and online learning experience as a response to an emergency (Hodges et al., 2020). This hurried shift online could be accepted as a temporary solution to a sudden problem but should not be accepted as a long-term solution. Work should be done to prepare for future emergencies.

The main area needing to be addressed was the approach to implementing e-learning. This ought to be based on a learner-centric and constructivist paradigm. Social presence and communication tools with psychologically-supportive elements being central such as multimedia materials. For this paradigm shift, first order barriers need to be considered Such barriers include the availability and accessibility of materials and devices, Internet connectivity and tutors' training. Only then can second-order barriers such as content and pedagogical strategies be addressed.

However, one success highlighted by this study came from the Omani government overcoming first order barriers when a royal directive was issued to provide free computer devices to new university students from low-income families (Oman Today, 2020).

Furthermore, this study found a lack of interrelation between first order experience and second order experience in participants' descriptions of their education. In Mezirow's theory, this relation is crucial for transformative learning. First order experience provides clues for learners to see second order experience and works as a prerequisite that is later extended. Similarly, the quality of second order experience enables receptivity and so makes learners ready for higher quality afterwards experience. In this study, as the two kinds of experiences for learners do not match, it could be concluded that the learners' experience during the pandemic was 'miseducative' as there is a noticeable 'under-familiarity' with e-learning (Malinen, 2000). However, learners received support during the pandemic from their university, family, friends, 
fellow students and surrounding environments. These providers of support worked as facilitators for transformative learning and there were some indicators of online transformative learning seen in students' attitudes, frames of reference and general perceptions of e-learning's usefulness.

The qualitative research shows the relationship between learner-centric teaching approaches and transformative learning. Similarly, students in Chi Ng's study (2007) were positive about the synchronous e-learning in the Interwise system and suggested more than one way of communicating.

I

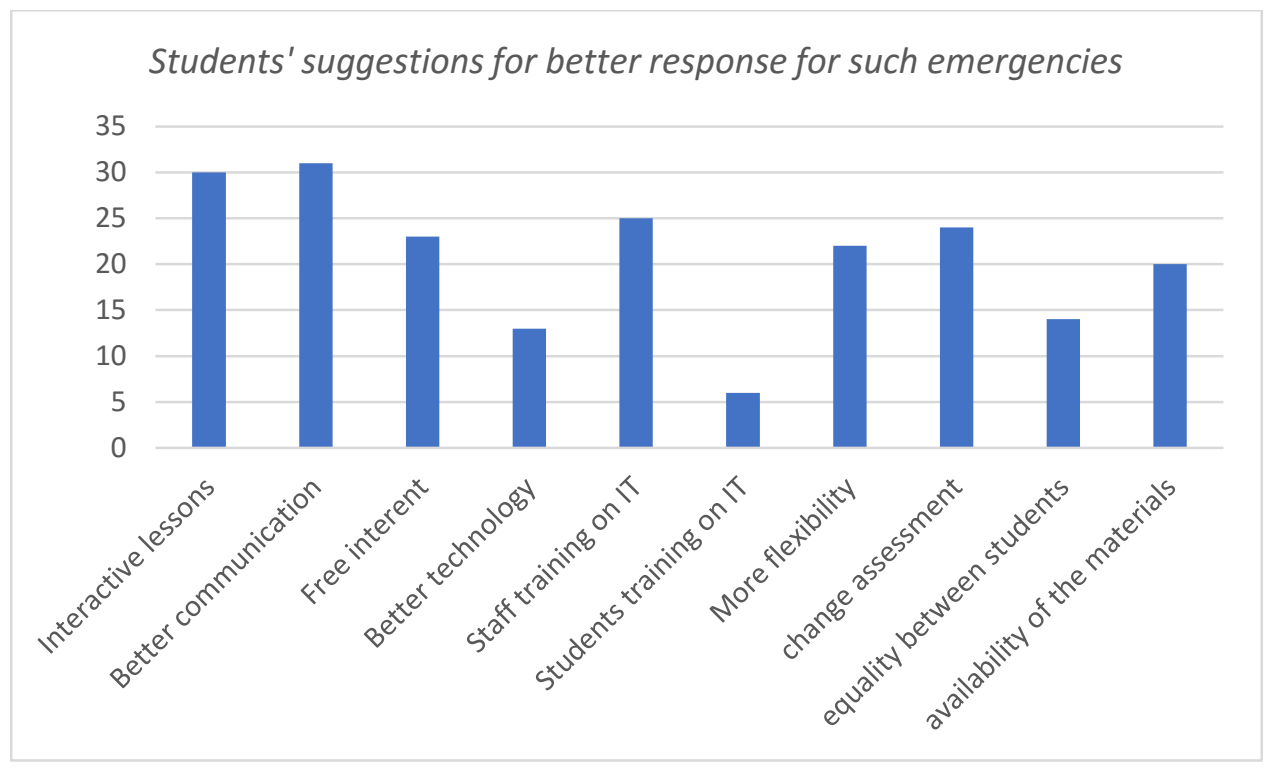

In this study, (69.4\%) of participants found their e-learning experience was not interesting or enjoyable. Cranton (2006) addresses the importance of personal transformation through imaginative tools which could include multi-media materials, visual-texts, and art which helps learners to enjoy their learning and become motivated. This soul work prepared students psychologically for transformative experience. One interviewee who learned advanced programming and designing skills for her own personal benefit contrasted the powerful transformative effects of the platforms she used with her university's learning management system of Moodle in terms of design, organization, use of colour and availability of interaction.

More respondents (48.2\%) did not perceive adopting e-learning as easy than the $34.3 \%$ who perceived ease. As one interview pointed out: 'It was a really difficult experience, but I could tell throughout the learning we did that I just could adapt' (INT3). For adopting full online learning, it is important that students hold a positive attitude toward technological intervention and are aware of its usefulness. This positive attitude is claimed to be gained with prior experience in e-learning as found in Welsh et al. (2003). Yet in a pressing situation, other factors may be important. In a study conducted on Palestine's students, they were found to prefer online learning over attending schools as online learning protects them from potentially fatal danger, although they did not have any prior experience in e-learning (Khitam \& Khlaif, 
2016). Participants in this study initially were resistant to learning remotely and their feelings were unsettled, yet this is generally normal in transformative learning online (Smith, 2012). Throughout the process of learning online during the pandemic, participants gained confidence and started to re-examine their habitual perceptions, confirming that they have suddenly realized the usefulness of e-learning not only to maintain their learning but helped them to acquire lifelong learning.

The qualitative research added important content which the quantitative research could not capture. Several students described the long-lasting benefits of the move to online learning. For example, one said, 'I became an autonomous learner' (P7), while another commented: 'I improved my time management' (P9). Another student said: 'I learned how to learn, how to search, how to study under pressure and how to balance the time between my study and my family' (P11).

This shows that students who were asked to learn online became autonomous learners, independent learners, able to capitalize their IT skills and communicative skills for the labour market. Some even said they should be ready for upcoming emergencies:

'Nothing is certain, we have to be ready for unpredictable situations, this experience gave me a new perspective on the whole world in a thoughtful way. This is a global pandemic, and people all over the world are the same, we have to rethink together' (INT2).

Overall, these findings tell us that although the outcomes of students' learning experience during the pandemic do not show clear transformative learning (Mean $=2.6$ ), students' responses show a willingness to adopt transformative learning (see chart 2). For example, students could reflect critically on this experience such as: 'The most important thing I learned at the personal level is to get ready for unexpected moments' (INT2). Another student said: 'It gave us responsibility and independence and the ability to prioritize our work ourselves' (INT1). Another student testified: 'I improved my autonomous study skills' (P6). Yet another student added detail: 'I improved my time management' (P9). Another student described transformation: 'I learned how to learn, how to search, how to study under pressure and how to balance the time between my study and my family' (P11). Some students described gaining valuable skills: 'I improved my virtual communication skills' (P21). Still another emphasized the long-lasting benefit of practical knowledge gained: 'I learned to gain skills that needed for work. Learning is not a matter of scores and numbers' (INT4).

\section{Conclusion}

The mixed method enabled me to gain a fuller picture than quantitative or qualitative analysis on its own could have done. The qualitative data converged with quantitative findings, which added strength to the quantitative data (Mertens, 2010). The deductive analysis I used enabled me to overcome the challenge of how to combine quantitative and qualitative data in the research outcomes. The qualitative research shows us learners self-reflectively assessing their own perceptions, a process called 'subjective reframing' by Mezirow (1997), which leads to significant personal development. That is, by self- reflection, learners can accomplish long term goals including autonomy, democracy and being active citizens, and can extend their 
perspective beyond merely short-term objectives such as the completion of a course or simply getting a job (Mezirow 1997). Yet this growth of intelligence and development of these higherlevel skills do not necessarily make lower-level skills irrelevant, as Piaget's theory states. They probably fall into disuse but are not to be rejected as the points of view arising from them become preconceptions and new concepts and meanings are generated through the conflict between familiar ideas and new and unfamiliar experiences (Mezirow, 1991).

In general, although the educational system in the Engineering Faculty at SQU tended not to be ready for the sudden shift to full e-learning, indicators of transformative learning have appeared during the COVID-19 pandemic experience when students were unable to attend SQU. These indicators are clear in learners' re-examining of their pre-established attitudes and perceptions of e-learning, a method which was viewed initially as merely complementary to traditional learning. However, through the process, they showed critical awareness of both the inadequacies of their first order experience of e-learning and of the lack of transformative facilitators in their second order experience. While their intellectual development may not make a significant difference to their previous traditional learning, they gained personal and affective development. As one participant said, 'This can be part of our life; we have to adjust to this change which perhaps will be a permanent change so that we won't return back to the previous form of learning. No one knows when this pandemic would end' (INT 2). Indeed, participants have become aware that they are also agents of change in whom e-learning promotes both liberation and transformation, helping them to become responsible, critical, independent and global learners (Smith 2012). Future study should examine content preparedness. The analysis of students' responses on social media to the complete shift to online learning revealed dissatisfaction. Disadvantaged groups including those with physical disabilities, mental health conditions, and neurodiverse conditions are often particularly adversely affected, as the online materials are simply a matter of content transfer, whereas what is needed is a reimagined online curriculum based on evidence coming from a successful crisis preparedness and response model (Rush et al. 2014). For a successful online learning environment, it is important to consider the design of the content, its layout and its accessibility (Shivetts. 2011). Therefore, a study is needed to explore online content suitability for all learners from different backgrounds and different learning styles. My study of e-preparedness is a first step. It shows both its potential for transformation and barriers we must focus on overcoming as we learn from the past and prepare for the future. 


\section{References}

Aydin, C. and Tasci, D., (2005). Measuring Readiness for e-Learning: Reflections from an Emerging Country. Educational Technology \& Society. [Online]. 8 (4). pp. 244-257. Available: https://www.jstor.org/stable/pdf/jeductechsoci.8.4.244.pdf

British Educational Research Association [BERA]., (2018). Ethical Guidelines for Educational Research [online]. $4^{\text {th }}$ ed. London. Available: https://www.bera.ac.uk/publication/ethicalguidelines-for-educational-research-2018

Caulfield, J., (2019). How to do Thematic Analysis? [Online]. Scribber. [Viewed 3 August 2020]. Available: https://www.scribbr.com/methodology/thematic-analysis/

Chi Ng, K., (2007). Replacing Face-to-Face Tutorials by Synchronous Online Technologies: Challenges and

pedagogical implications. International Review of Research in Open and Distance Learning [online]. 8(1), 1-15. Available: https://doi.org/10.19173/irrodl.v8i1.335

Cohen, L., Manion, L., \& Morrison, K. (2007). Research Methods in Education. 6th ed. Routledge

Costley, C., Elliott, G., \& Gibbs, P. (2010). Doing Work Based Research: Approaches to Enquiry for Insider - Researchers. SAGE

Cranton, P., (2006). Fostering authentic relationships in the transformative classroom. Teaching for Change: Fostering Transformative Learning in the Classroom [online]. 2006(109), 5-13. Available: https://doi.org/10.1002/ace.203

Creswell, J., (2014). Doing Research Design. $4^{\text {th }}$ ed. SAGE

Crow, G. \& Wiles, R. (2008). Managing anonymity and confidentiality in social research: the case of visual data in Community research. Southampton: University of Southampton. [Unpublished item].

Creemers, B. \& Kyriakides, L. (2006). Critical analysis of the current approaches to modelling educational effectiveness: The importance of establishing a dynamic model. School Effectiveness and School Improvement [online]. 17(3), 347-366. Available: doi: $10.1080 / 09243450600697242$

Creswell, J. \& Stick, Sh., (2006). Using Mixed-Methods Sequential Explanatory Design: From Theory to Practice. Field Methods [online]. 18(1), 3-12. Available: doi: $10.1177 / 1525822 \mathrm{X} 05282260$

Creswell, J., (2009). Research Design. $3^{\text {rd }}$ ed. SAGE

Denscombe, M., (2010). The good research guide for small-scale research projects. $\left(4^{\text {th }} \mathrm{ed}.\right)$. Open University Press. 
Damayanthi, S., (2019). Thematic Analysis of Interview Data in the Context of Management Controls Research [online]. London: SAGE. Available: https://dx.doi.org/10.4135/9781526474858

Gibson, L., (2017). Virtual Data Collection. In: V. Braun, V. Clarke and D. Gray, eds. Collecting Qualitative Data: a practical guide to textual, media and virtual techniques [online]. Cambridge: Cambridge University Press. pp. 189210. Available: https://doi.org/10.1017/9781107295094

Haverila, M., (2012). The Biggs and Moore Model in e-learning: The role of motivation and collaboration as moderators. Turkish Online Journal of Distance EducationTOJDE [online]. 13(2), 169-179. Available: doi: https://eric.ed.gov/?id=EJ983653

Hodges, et al., (2020). The Difference Between Emergency Remote Teaching and Online Learning [online]. EDUCAUSE Review. Available

: https://er.educause.edu/articles/2020/3/the-difference-between-emergency-remote-teachingand-online-learning

Keegan, P., (2011). Transformative e-Learning and Teaching in Mandatory Tertiary Education. Asian Social Science [online]. 7(11), 66-74. Available: doi: 10.5539/ass.v7n11p66

Khitam, Sh. \& Khlaif, Z., (2010). Students' Readiness Towards E-learning: A case study of Virtual Classrooms for secondary education in Palestine. The 3rd Annual Forum on e-learning Excellence in the Middle East, 2010, Dubai, UAE [online]. Available : doi: https://scholar.ptuk.edu.ps/handle/123456789/677

King, N., (2004). Using Templates in the thematic analysis of text. In: C. Cassell and G. Symon, eds. Essential Guide for Qualitative Methods in Organisational Research. SAGE. pp. 256271.

Lefever, S. et al., (2007). Online data collection in academic research: advantages and limitations. British Journal of Educational Technology [online]. 38 (4), 574-582. Available: doi:10.1111/j.1467-8535.2006. 00638.x

Liaw, S., (2004). Considerations for developing constructivist web-based learning. International Journal of Instructional Media [online]. 31(3), 309321. Available: https://www.researchgate.net/publication/291979640_Considerations_for_de veloping_constructivist_web-based_learning

Mezirow, J., (2009). An overview of transformative learning. In: K. Illeris, ed. Contemporary theories of learning, learning theories...in their own words. Routledge. pp. 90-106.

Malinen, A., (2000). Adult Experiential Learning. University of Jyvaskyla: SoPhi

Matthews, B. and Ross, L., (2010). Research Methods: A practical guide for the social sciences. 1st ed. Pearson Education 
Mezirow, J., (1997). Transformative Learning: Theory to Practice. New Directions for Adult and Continuing Education [online]. (74), 5-12. Available: https://doi.org/10.1002/ace.7401

MoH., (2020). MOH Alert: Corona virus Disease (COVID-19) [online]. MoE. Available: https://moh.gov.om/ar/web/guest/-/moh-alert-corona-virus-disease$\underline{\text { covid-1-2 }}$

Nowell, L. et al., (2017). Thematic Analysis: Striving to Meet the Trustworthiness Criteria. International Journal of Qualitative Methods [online]. 13(1), 113. Available: https://doi.org/10.1177\%2F1609406917733847

Okinda, R., (2014). Assessing E-Learning Readiness at the Kenya Technical Teachers College. Journal of Learning for Development [online]. 1(3), 112. Available: http://j14d.org/index.php/ej14d/article/view/32

O’Leary, Z., (2004). Guide to Doing Research. SAGE.

Oman Today., (2020). Oman's Sultan Haitham orders free laptops for new students [online]. Oman Today. Available: https://omanonline.media/omans-sultan-haithamorders-free-laptops-for-new-students/

Poland, B., (2011). Transcription Quality. In: J. Gubrium and J. Holstein, eds. Handbook of Interview Research [online]. SAGE . Available: https://dx.doi.org/10.4135/9781412973588.n36

Reimers, F. \& Schleicher, A., (2020). A framework to guide an education response to the COVID-19 Pandemic of 2020 [online]. Harvard: OECD. Available: https://doi.org/10.15694/mep.2020.000082.1

Smith, R., (2012). Transformative Learning Online. In: E. Taylor and P. Cranton, eds. The Handbook of Transformative Learning. Jossy-Bass. pp. 408-425.

Subedi, D., (2016). Explanatory Sequential Mixed Method Design as the Third Research Community of Knowledge Claim. American Journal of Educational Research [online]. 4(7), 570-577. Available: doi: 10.12691/education-4-7-10

Unal, Y. and Soydal, I., (2014). Students Readiness for E-Learning: An Assessment on Hacettepe University, Department of Information Management. Challenges of Information Management Beyond the Cloud [online]. 423, 137147. Available: https://doi.org/10.1007/978-3-662-44412-2_13

Welsh, E., et al., (2003). E-learning: emerging uses, empirical results and future directions. International journal of training and development [online]. 7(4), 245258. Available: https://doi.org/10.1046/j.1360-3736.2003.00184.x 